Samira Emami and Mir Mohammad Alavi Nikje*

\title{
Environmentally benign chemical recycling of polycarbonate wastes: comparison of micro- and nano-TiO 2 solid support efficiencies
}

https://doi.org/10.1515/gps-2018-0028

Received January 21, 2018; accepted March 22, 2018; previously published online May 24, 2018

Abstract: Polycarbonate (PC) wastes, including optical discs (CDs) and digital optical discs (DVDs), were chemically recycled into valuable materials such as $4,4^{\prime}$-(propane-2,2-diyl)diphenol (BPA) and etherified derivatives of BPA using sodium hydroxide $(\mathrm{NaOH})$ as the alkali metal catalyst and nanostructured titanium dioxide $\left(\right.$ nano- $\left.\mathrm{TiO}_{2}\right)$ and microstructured titanium dioxide $\left(\right.$ micro-TiO $\left._{2}\right)$ as the solid supports in the binary green system consisting of water and 2,2'-oxydi(ethan-1-ol) (DEG) under conventional heating method, and data were compared. In this study, the effects of various parameters, such as solvent composition, concentration of $\mathrm{NaOH}$, and solid support, were studied on the reaction progress. In these reactions, the importance of water as the green solvent was investigated in achieving pure BPA as the valuable material. When used with $20 \%$ aqueous DEG (pbw), a pure BPA can be obtained at $70 \%$ yield in the presence of nano-TiO ${ }_{2}$ and micro- $\mathrm{TiO}_{2}$ as the solid supports. According to the results, the use of nano- $\mathrm{TiO}_{2}$ in comparison with micro- $\mathrm{TiO}_{2}$ accelerates the chemical recycling of $\mathrm{PC}$ wastes. The nano-TiO catalyst recovery shows that the recovered solid support is applicable for four cycles. The obtained products were characterized using spectroscopic methods, namely, ${ }^{1} \mathrm{H}$ NMR, ${ }^{13} \mathrm{C}$ NMR, and Fourier transform infrared spectroscopy as well as gas chromatography-mass spectrometry.

Keywords: bisphenol-A; chemical recycling; green chemistry; nano- $\mathrm{TiO}_{2}$; solid support.

\footnotetext{
*Corresponding author: Mir Mohammad Alavi Nikje, Department of Chemistry, Faculty of Science, Imam Khomeini International University, P.O. Box 288, Qazvin, Iran, e-mail: Drmm.alavi@gmail.com
}

Samira Emami: Department of Chemistry, Faculty of Science, Imam Khomeini International University, P.O. Box 288, Qazvin, Iran

Ә Open Access. (cc)BY (C) 2019 Walter de Gruyter GmbH, Berlin/Boston

\section{Abbreviations}

$\begin{array}{ll}{ }^{1} \mathrm{H} \text { NMR } & \text { proton nuclear magnetic resonance } \\ { }^{13} \mathrm{C} \mathrm{NMR} & \text { carbon-13 nuclear magnetic resonance } \\ \text { BGA-BPA } & \text { mono glycerol ether of BPA } \\ \text { BHE-BPA } & \text { bis(hydroxy ethyl) ether of bisphenol-A } \\ \text { BPA } & \text { bisphenol-A } \\ \mathrm{CDCl}_{3} & \text { chloroform-d } \\ \mathrm{CDs} & \text { optical discs } \\ \text { DGA-BPA } & \text { diglycerol ether of BPA } \\ \text { DMC } & \text { dimethyl carbonate } \\ \text { DVDs } & \text { ethylene carbonate } \\ \text { EC } & \text { ethylene glycol } \\ \text { EG } & \text { Fourier transform-infrared spectroscopy } \\ \text { FT-IR } & \text { gas chromatograph } \\ \text { GC } & \text { gas chromatography-mass spectrometry } \\ \text { GC-MS } & \text { liquid crystal display } \\ \text { LCD } & \text { melting point } \\ \text { m.p. } & \text { mono(hydroxy ethyl) ether of bisphenol-A } \\ \text { MHE-BPA } & \text { microstructured titanium dioxide } \\ \text { Micro-TiO } & \text { nanostructured titanium dioxide } \\ \text { Nano-TiO } & \text { polycarbonate } \\ \text { PC } & \text { polyurethanes } \\ \text { PUR } & \text { tetrahydrofuran } \\ \text { THF } & \text { tetramethylsilane } \\ \text { TMS } & \text { X-ray diffractometer } \\ \text { XRD } & \end{array}$

\section{Introduction}

Polycarbonate (PC) as a useful engineering thermoplastic due to its unique properties is widely used in various applications such as in medical, security compounds, construction materials, data storage, phones, liquid crystal display (LCD) screens, electronic component, bottles, laboratory safety goggles, automotive, aircraft, optical discs (CDs), and digital optical discs (DVDs). Because of unprecedented increase in $\mathrm{PC}$ wastes, recycling expansion in recent years has become necessary. In general, there are two methods that have been developed for recycling of PC wastes, which are the physical and chemical methods. In the chemical method, the PC wastes can be turned into 4,4'-(propane-2,2-diyl)diphenol (BPA), bis(hydroxy ethyl) ether of BPA (BHE-BPA), and mono(hydroxy ethyl) ether of BPA (MHE-BPA) using ethane-1,2-diol (EG) as the solvent, 
sodium hydroxide $(\mathrm{NaOH})$ as the alkali metal catalyst, and 1,3-dioxolan-2-one (EC) as the reagent [1]. Semi-continuous lab-plant is another chemical method, studied by using a destructive reagent, such as methanol and methanolwater mixtures, on PC that is converted to BPA (99.9\%) and dimethyl carbonate (DMC, 35\%) [2]. In another study, metal chlorides, namely, tin dichloride $\left(\mathrm{SnCl}_{2}\right)$ and zinc chloride $\left(\mathrm{ZnCl}_{2}\right)$, catalytic efficiencies had been studied on the thermal degradation of PC wastes [3]. Moreover, Pant studied recycling of PC wastes by using glycerol as the solvent in combination with mild catalysts such as zinc oxide $(\mathrm{ZnO})$ and sodium carbonate $\left(\mathrm{Na}_{2} \mathrm{CO}_{3}\right)$ in the presence or absence of urea $\left(\mathrm{CO}\left(\mathrm{NH}_{2}\right)_{2}\right)$. In these reactions, monoglycerol ether of BPA (BGA-BPA), diglycerol ether of BPA (DGA-BPA), and BPA were obtained [4]. Iannone and his co-workers studied the efficiency of nanostructured $\mathrm{ZnO}$ and tetrabutylammonium chloride (ZnO-nanoparticles/ $\left.\mathrm{NBu}_{4} \mathrm{Cl}\right)$ as a recyclable catalyst on the PC depolymerization into BPA monomer under the following conditions: tetrahydrofuran (THF) as solvent, $7 \mathrm{~h}, 100^{\circ} \mathrm{C}$, and nitrogen $\left(\mathrm{N}_{2}\right)$ atmosphere [5]. In another study, Li et al. [6] described controllable PC depolymerization by using 1,4-dioxane/EG as the solvents and zinc acetate $\left(\mathrm{Zn}\left(\mathrm{O}_{2} \mathrm{CCH}_{3}\right)_{2}\right)$ as the catalyst. In addition, in high temperature of $300^{\circ} \mathrm{C}$, BPA was obtained in $91 \%$ yield under pyrolytic hydrolysis conditions of $\mathrm{PC}$; when temperature is raised to $500^{\circ} \mathrm{C}$, this product degraded [7]. Following an overview on recycling of PC wastes, recycling of PC wastes by alkali-catalyzed methanolysis and hydrolysis reactions led to recover BPA in 94\% yield [8]. In the meantime, recycled PC via the methanolysis chemical method in the presence of $n$-butyl-3-methylimidazolium chloride ([Bmim] $[\mathrm{Cl}]$ ) as the ionic liquid at $105^{\circ} \mathrm{C}$ for $2.5 \mathrm{~h}$ without applying acidic or basic catalysts collected BPA and DMC in good yields [9]. Moreover, PC depolymerization using an alcohol such as supercritical ethanol has been studied [10]. BPA was recovered as the sole product using 1-butyl-3-methylimidazolium acetate ([Bmim] [AC]) as the ionic liquid at $140^{\circ} \mathrm{C}$ [11]. In explaining the mechanism of glycolysis reactions in the destruction of PC, two mechanistic pathways were suggested by Kim's research group [12]. Beneš et al. [13] studied the two-step solvent-free recycling process of $\mathrm{PC}$ into suitable polyols for the synthesis of novel polyurethanes (PUR) using glycerol for oil transesterification, coconut oil as solvolysis reagent, and dibutylbis[1-oxo(dodecyl)oxy]stannane (DBTL) as a catalyst. Taguchi and co-workers studied the chemical recycling of PCs into BPA with $90 \%$ yield under hydrothermal conditions using a batch reactor in the presence of two crystallite sizes of cerium (IV) oxide $\left(\mathrm{CeO}_{2}\right)$ crystal (75 and $7.4 \mathrm{~nm}$ ) as the catalyst [14]. Moreover, more methods and studies are presented for the chemical recycling of PC involving alcoholysis [15-17], aminolysis [18, 19], pyrolysis [20-22], hydrolysis [23-26], and hydrolysis/glycolysis [27]. In our previous works, the chemical recycling of PC wastes into BPA has been considered in the presence of green solvents such as (water, glycerol, and sorbitol) mixtures [28], (water and glycerol) mixtures [29], and water [30] under conventional heating method and (water and glycerol) mixtures [31], and EG [32] under conventional microwave irradiation using $\mathrm{NaOH}$ as alkali metal catalyst. In our previous researches, the amount of $\mathrm{NaOH}$ as alkali metal catalyst $(0.5 \%$ to $2 \%$ based on total waste and solvent weights) and the weight ratios PC pellets:solvent was 1:1. In addition, in one of the last studies mentioned, the effects of the nanostructures such as Closite 30B, silicon dioxide $\left(\mathrm{SiO}_{2}\right)$, and titanium dioxide $\left(\mathrm{TiO}_{2}\right)$ as solid supports ( $2 \%$ based on total waste and solvent weights) on the chemical recycling of PC wastes have been studied [30]. In this case, we decided to estimate the efficiency of titanium dioxide $\left(\mathrm{TiO}_{2}\right)$ in two scales of nanostructure (nano- $\mathrm{TiO}_{2}$ ) and microstructure $\left(\right.$ micro- $\mathrm{TiO}_{2}$ ) as the eco-friendly, non-toxic, low-cost, chemically stable, and recyclable solid supports in the chemical recycling of PC wastes. Our main goal in the current report is the chemical recycling of PC wastes to pure BPA as the valuable material in accordance with the main goals of green chemistry and synthesis using green solvent composition, namely, 2,2'-oxydi(ethan-1-ol) (DEG) and water, in combination with a least amount of alkali metal catalysts in an easy and ecofriendly method in the presence of nano- and micro-TiO ${ }_{2}$ as an efficient solid support at atmospheric pressure. In these reactions, valuable materials such as BPA and etherified derivatives of BPA were identified. In this study, the presence of water is known as an eco-friendly solvent to achieve pure $\mathrm{BPA}$. According to the results, when nano- $\mathrm{TiO}_{2}$ as the solid support are used in the reaction mixtures, the chemical recycling of PC wastes is accelerated compared with the experimental conditions using $\operatorname{micro}-\mathrm{TiO}_{2}$ as the solid support. The nano-solid support can be recovered for four cycles and used in the next reaction.

\section{Materials and methods}

\subsection{Materials}

$\mathrm{NaOH}$, methanol (MeOH), DEG, acetic acid (MeCOOH), and acetone $\left(\mathrm{C}_{3} \mathrm{H}_{6} \mathrm{O}\right)$ were purchased from Merck company (Darmstadt, Germany) and used as received without further purification. PC pellets were obtained from CD and DVD wastes, and the thin layer of aluminum was separated completely. Then, the large particles of PC wastes were broken into the arbitrary sizes and shapes (very tiny pieces), washed with $\mathrm{NaOH}$ solution and hot water for several times, and then dried. 
The water for doing the reactions was twice distilled. Nano-TiO ${ }_{2}$ were purchased from Kemira company (Helsinki, Finland) with the average crystallite size of $34.68 \mathrm{~nm}, 79.75 \%$ rutile, and $20.25 \%$ anatase phases and specific surface area of $59 \mathrm{~m}^{2} / \mathrm{g}$. Moreover, micro- $\mathrm{TiO}_{2}$ was supplied from the Crimea Titan company (Crimea, Ukraine).

\subsection{Instruments}

Fourier transform-infrared spectroscopy (FT-IR) spectra ( $\mathrm{KBr}$ pellet press in a weight ratio of 1:100 sample/KBr) were recorded on a BRUKER Tensor 27 spectrometer (Bruker, Billerica, MA, USA) between 400 and $4000 \mathrm{~cm}^{-1} .{ }^{1} \mathrm{H}$ and ${ }^{13} \mathrm{C}$ NMR spectra were recorded on a BRUKER CRX 300 spectrometer (at $300 \mathrm{MHz}$, Bruker, Billerica, $\mathrm{MA}$, USA) employing indicated solvents $\mathrm{CDCl}_{3}$ and tetramethylsilane (TMS) and the internal standard, respectively. Chemical shifts are expressed in ppm $(\delta)$ values and coupling constants in $\mathrm{Hz}(J)$. Melting point was determined on a Gallenkamp electrothermal 9100 (CO, USA). The nanostructure (nano- $\mathrm{TiO}_{2}$ ) was characterized on an X-ray diffractometer (XRD, Model: GNR, Novara, Italy). The XRD data were collected on an APD-2000 diffractometer ( $\mathrm{Cu}$ K $\alpha$ radiation, $\lambda=1.54 \AA$, GNR, Novara, Italy) from $20^{\circ}$ to $80^{\circ}(2 \theta)$. Nanostructure recycling processes were done on a centrifuge (Centromix, JP Selecta s.a., Kyoto, Japan, 5890g) instrument. Moreover, materials and products were dried using a vacuum oven (Wisd, WOV-70, DAIHAN Scientific, Seoul, South Korea) in the reactions. The obtained products were characterized using an Agilent/HP 6890 gas chromatograph (GC) combined with a 5973 MSD (Mass Spec, Mass Spectrometer, Mass Selective Detector, MS, GC-MS, Agilent, Santa Clara, CA, USA). In addition, samples for GC-MS analysis were dissolved in $\mathrm{MeOH}$. The temperature program of the GC column used was as follows: temperature kept at $60^{\circ} \mathrm{C}$ for the first $1 \mathrm{~min}$ and then increased to $285^{\circ} \mathrm{C}$ for $14 \mathrm{~min}$ using a heating rate of $20^{\circ} \mathrm{C} \mathrm{min}^{-1}$.

\subsection{General procedure}

In this section, the process was carried out in a $50 \mathrm{ml}$ two-necked bottom equipped with a magnetic stirrer, and a reflux condenser and filled with $5.0 \mathrm{~g}$ of PC wastes pellets, DEG and water (total weight of solvents $5.0 \mathrm{~g}$ ), and $\mathrm{NaOH}$ ( $2 \%$ based on total weights of the PC waste and solvent $=0.2 \mathrm{~g}$ ) as the alkali metal catalyst. In addition, microor nano- $-\mathrm{TiO}_{2}$ as the solid support $(2 \%$ based on total weights of the $\mathrm{PC}$ waste and solvent $=0.2 \mathrm{~g}$ ) was added to the reaction vessel. As a general procedure, the reaction vessel was heated under reflux, and complete dissolution of the PC wastes was considered as the reaction end point. The weight ratios (PC pellets:solvents) and (alkali metal catalyst or solid support:PC pellets) were 1 and 0.04 , respectively. In the next step, the reaction mixture was cooled to room temperature and neutralized with acetic acid as noted in Tables 1 and 2. Product recovery yields are obtained using Eq. (1). Moreover, purification of the obtained products was performed by methanol:water 1:1 mixture solution $(30 \mathrm{ml})$, and the product was separated by filtrating, washed with twice distilled water for several times, dried at $80^{\circ} \mathrm{C}$ in vacuum oven for $5 \mathrm{~h}$, and then characterized by using spectroscopic methods ( ${ }^{1} \mathrm{HNMR},{ }^{13} \mathrm{CNMR}$, and FT-IR) and GC-MS.

$$
Y=\frac{b}{a} \times 100 \%
$$

Table 1: $\mathrm{DEG} /$ water composition role using nano- $\mathrm{TiO}_{2}$ as the solid support in chemical recycling of PC wastes.

\begin{tabular}{lrrr}
\hline Entry & DEG:water (Pbw) & $\boldsymbol{t}(\boldsymbol{m i n})$ & Product recovery yield (\%) \\
\hline 1 & $100: 0$ & 13 & 85 \\
2 & $90: 10$ & 22 & 75 \\
3 & $80: 20$ & 88 & 70 \\
4 & $70: 30$ & 95 & 65 \\
5 & $60: 40$ & 251 & 53 \\
6 & $50: 50$ & 332 & 40 \\
\hline
\end{tabular}

Table 2: DEG/water composition role using micro- $\mathrm{TiO}_{2}$ as the solid support in chemical recycling of PC wastes.

\begin{tabular}{lrrr}
\hline Entry & DEG:water $(\mathrm{Pbw})$ & $\boldsymbol{t}(\mathrm{min})$ & Product recovery yield (\%) \\
\hline 1 & $100: 0$ & 17 & 80 \\
2 & $90: 10$ & 53 & 73 \\
3 & $80: 20$ & 110 & 70 \\
4 & $70: 30$ & 160 & 63 \\
5 & $60: 40$ & 320 & 52 \\
6 & $50: 50$ & 360 & 40 \\
\hline
\end{tabular}

where $Y$ is the product recovery yield (\%), $b$ is the amount of recovered products in the chemical recycling of PC wastes (g), and $a$ is the amount of PC wastes used in the chemical recycling of PC wastes (g).

\section{Results and discussion}

\subsection{Reaction scheme}

According to all identified products, the proposed hydroglycolysis reaction of PC wastes under alkali metal catalyzed is shown in Scheme 1. As shown in the scheme, the reaction was explained with a Brønsted-Lowry acid-base reaction and conversion of DEG molecules to the corresponding alkoxide ion that is responsible for acting as a nucleophile with attaching to the carbonate functional group of PC and formation of products 1 . In the next step, the other products were made in the reaction media.

\subsection{Solvent composition studies}

According to our results, by increasing the water content in the solvent composition $(0 \%-50 \%$ based on total solvent weights), the concentration of the hydroxide ion as a nucleophile increases and competes with the alkoxide ion from DEG molecules in reacting with the carbonate functional group resulting in an extended reaction time due to its lesser nucleophilicity when compared by 

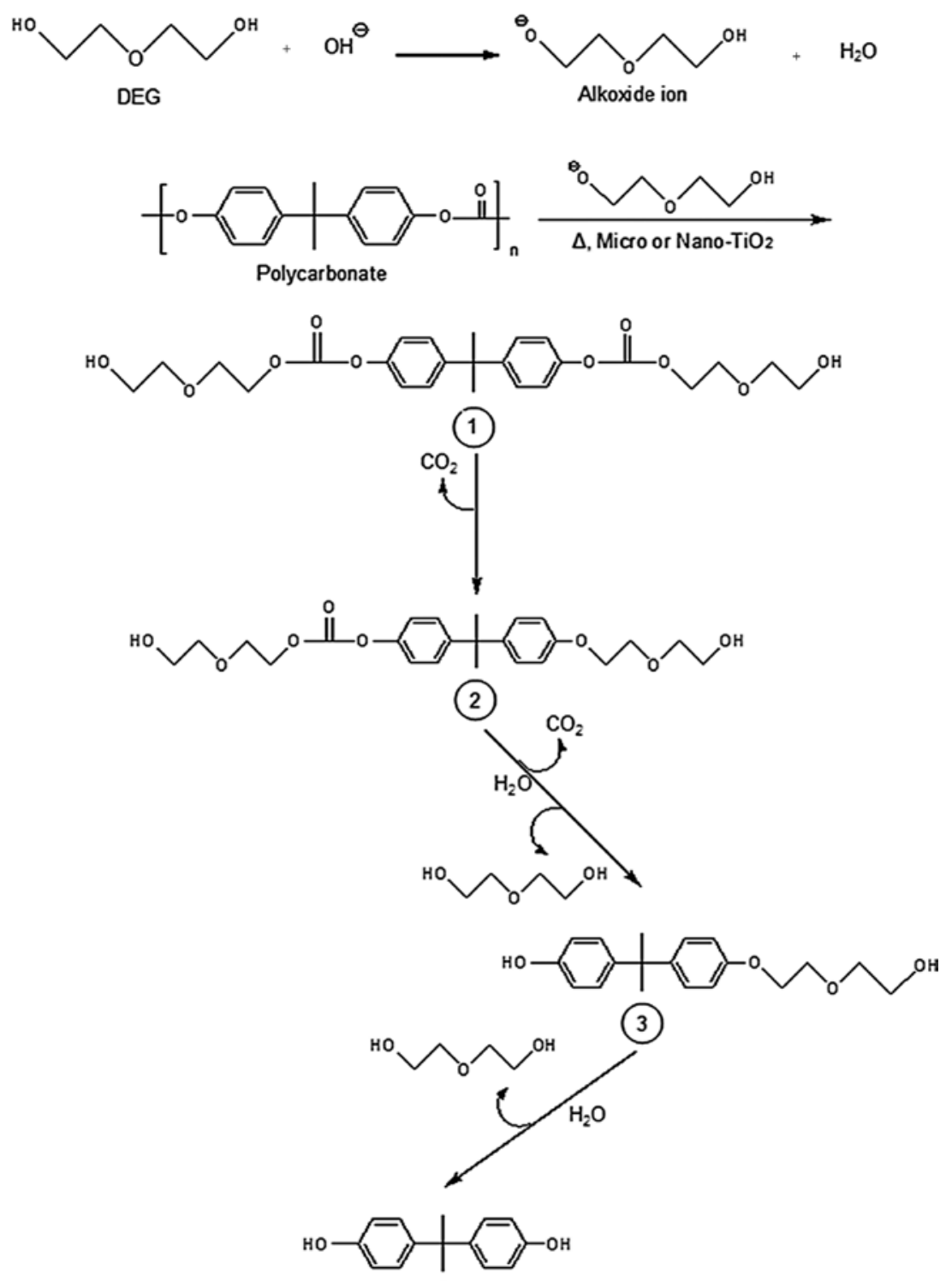

(4)

Scheme 1: Reaction and mechanism: (1) Bis(2-(2-hydroxyethoxy)ethyl)(propan-2,2-diylbis(4,1-phenylene))dicarbonate (MW=490); (2) 4-(2-(4-(2-(2-hydroxyethoxy)ethoxy)phenyl)propan-2-yl)phenyl(2-(2-hydroxyethoxy)ethyl)carbonate (MW=448); (3) 4-(2-(4-(2-(2-hydroxyethoxy)ethoxy)phenyl)propan-2-yl)phenol (MW=316); (4) 4,4'-(propane-2,2-diyl)diphenol (MW=228); DEG) 2,2'-oxydi(ethan-1-ol); $\Delta=$ heat; $M W=$ molecular weight.

the alkoxide ion. In order to find a green solvent composition in accordance with the main goals of green chemistry and synthesis containing higher levels of the water, the effects of various ratios of DEG and water were studied in chemical recycling of $\mathrm{PC}$ wastes, and data are collected in Tables 1 and 2 using nano- $-\mathrm{TiO}_{2}$ and micro-TiO ${ }_{2}$ as the solid support, respectively. As one can see, the highest recovery of product was achieved under the conditions remarkable in entry 3 in Tables 1 and 2 using 20 pbw aqueous DEG (in Section 3.6, it will be discussed that the purpose of the highest recovery of product in entry 3 in Tables 1 and 2 is pure BPA as a valuable material). Product recovery yields are reduced by increasing the amount of water in the reaction media.

\subsection{Study on alkali metal catalyst concentration}

To study the role of alkali metal catalyst concentration in the reaction progress as well as product formation, a set of experiments was carried out using additional 0.5 to 
Table 3: Catalyst concentration role using nano- $\mathrm{TiO}_{2}$ as the solid support in chemical recycling of PC wastes.

\begin{tabular}{lrr}
\hline Entry & Catalyst concentration (Pbw) & $\boldsymbol{t}$ (min) \\
\hline 1 & 1.5 & 150 \\
2 & 1 & 200 \\
3 & 0.5 & 250 \\
\hline
\end{tabular}

$1.5 \mathrm{pbw} \mathrm{NaOH}$ as alkali metal catalyst and nano- $\mathrm{TiO}_{2} 2 \mathrm{pbw}$ as the nano-solid support and the DEG:water two systems as 80:20 ratio. The results are collected in Table 3, and data are compared by obtaining data in the Table 1. By comparison of the results, it is concluded that by decreasing of the $\mathrm{NaOH}$ concentration in the chemical recycling of PC wastes, the reaction completed in the prolonged times when compared with high concentrated reactions (Scheme 2). It is also quite clear that by increasing the catalyst concentration from $2 \mathrm{pbw}$, the time to complete the reaction will be reduced. On the other hand, the significant increase in reaction time in the case of reduction of the alkali metal catalyst concentration is not appropriate for the main goals of green chemistry and synthesis. According to the main goals of green chemistry and synthesis, regarding these experiments, the base catalyst concentration was set as $2 \mathrm{pbw}$ in all reactions.

\subsection{The role of the solid support at nanoscale}

The X-ray diffraction pattern of nano- $\mathrm{TiO}_{2}$ at positions $(2 \theta)$ 27.22, 35.9, 39.05, 41.09, 43.92, 54.26, 56.42, 62.58, 63.96,

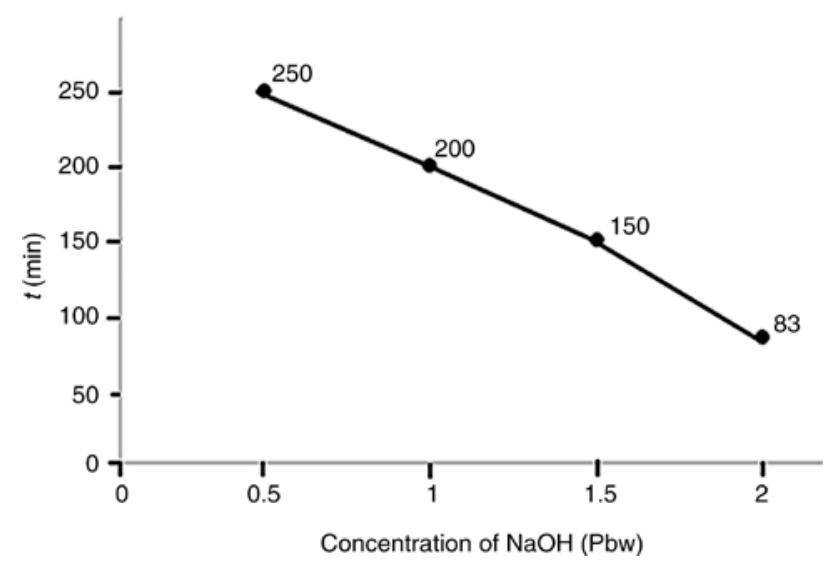

Scheme 2: The effect of alkali metal catalyst concentration in the PC dissolution time: DEG (4.0 g); water (1.0 g); DEG/water (80:20 pbw); PC wastes (5.0 g); NaOH and nano- $\mathrm{TiO}_{2}(2 \mathrm{pbw}) ; \mathrm{PC}$ wastes:solvent (1:1).

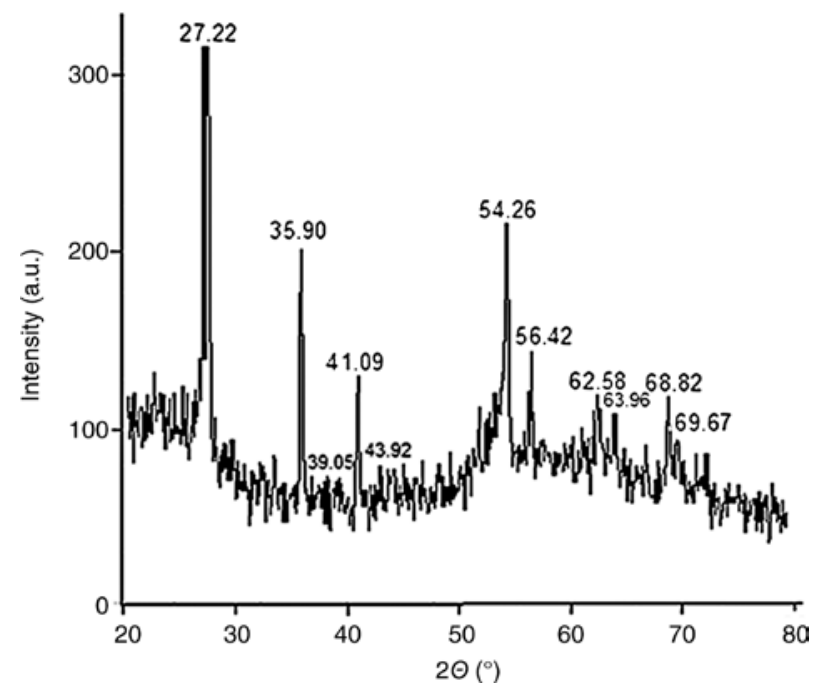

Scheme 3: XRD spectra of nanostructured $\mathrm{TiO}_{2}$.

68.82, and 69.67 as main angles are shown in Scheme 3. The average nano-TiO diameter was calculated to be $34.68 \mathrm{~nm}$ from the XRD results by using the Debye-Scherrer's Eq. (2) and $2 \theta=27.22^{\circ}$ in the Supplementary Material. Moreover, the observed XRD peaks were well assigned to rutile $\mathrm{TiO}_{2}$ mainly [33]. In the presence of about $79.75 \%$ rutile and $20.25 \%$ anatase, phases were determined approximately in the XRD analysis (Supplementary Figure S22). The

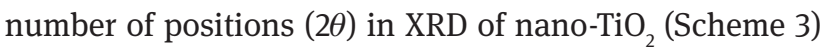
is due to the combination of two phases of the rutile and anatase. In the following, in order to investigate the role of solid support at the nanoscale, experiments were carried out by using micro-TiO 2 pbw, and $\mathrm{NaOH} 2$ pbw as alkali metal catalyst (Table 2), and the data were compared with nominated experiments of nano- $\mathrm{TiO}_{2}$ in the Table 1 . These

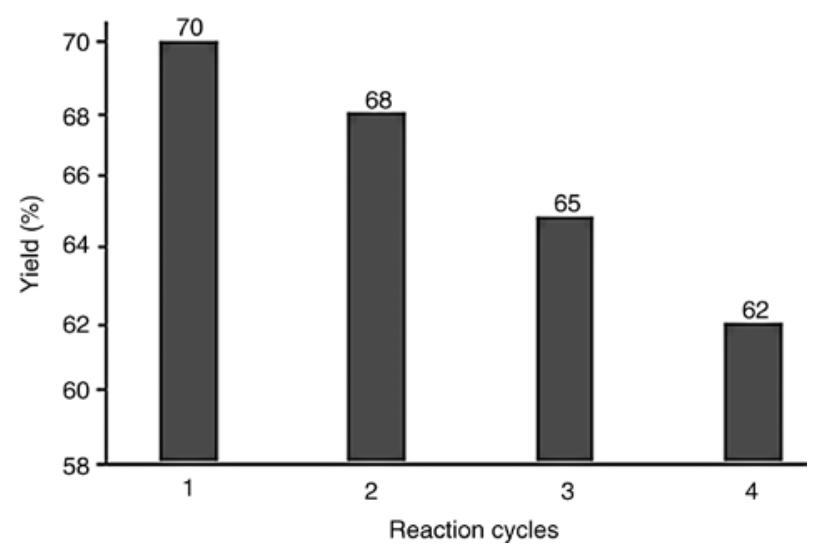

Scheme 4: The effect of reuse of nano- $\mathrm{TiO}_{2}$ as the solid support on the chemical recycling of PC wastes: DEG (4.0 g); water (1.0 g); DEG/ water (80:20 pbw); PC wastes (5.0 g); $\mathrm{NaOH}$ and nano- $\mathrm{TiO}_{2}(2 \mathrm{pbw})$; $\mathrm{PC}$ wastes: solvent (1:1); reaction time (83 $\mathrm{min})$. 
results show significant increments in reaction times due to a reduction of the surface to volume ratio when micro$\mathrm{TiO}_{2}$ was used as the solid support.

$$
D=\frac{k \lambda}{\beta \cos \theta}
$$

where $k$ is generally considered as $0.94 ; \lambda$ is the wavelength of $\mathrm{Cu} \mathrm{K} \alpha, 1.54 \AA^{\circ} ; \beta$ is the full-width at half-maximum; and $\theta$ is the Bragg's angle $\left(^{\circ}\right)$ [34].

\subsection{Recycling of nano-TiO 2 as the solid support}

As the catalyst recovery is one of the main goals of the green chemistry and synthesis, the recycling of nano- $\mathrm{TiO}_{2}$ as the nano-solid support was examined under the conditions remarkable in entry 3 in Table 1 . In the first step, the PC wastes dissolved completely within $83 \mathrm{~min}$, and then the order of the purification steps described in Section 2.3

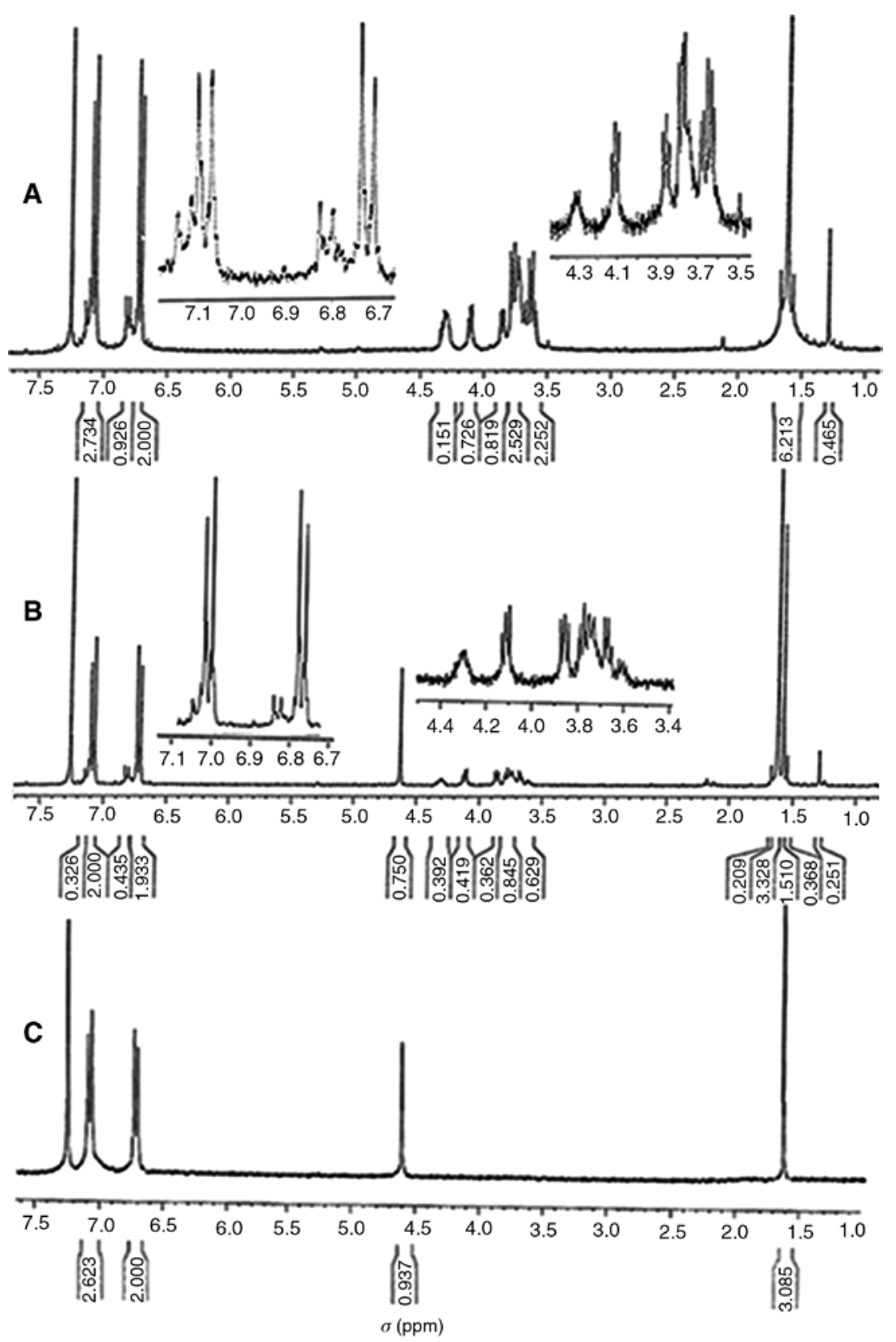

Scheme 5: ${ }^{1} \mathrm{H}$ NMR spectra in the $\mathrm{CDCl}_{3}$ solvent: (A) Blended product resulting from the absence of water; (B) (BPA+byproduct) is resulting from the $10 \%$ water; (C) BPA resulting from more amount of water in the reaction medium. 
in recovering the product was carried out. In the next step, the product was dissolved in acetone, and the nano-solid support was separated with a centrifuged colloidal solution and were washed with acetone and water for several times and dried. Other reactions were performed with the recycled nano- $\mathrm{TiO}_{2}$ as the solid support. Scheme 4 shows the activity of nano-TiO ${ }_{2}$ as the solid support in product recovery after four cycles, and the recovery yield drops dramatically.

\subsection{Characterization of products using identification methods $\left({ }^{1} \mathrm{H}\right.$ NMR, ${ }^{13}$ C NMR, FT-IR, and GC-MS)}

Products resulted from chemical recycling of PC wastes were analyzed using identification methods $\left({ }^{1} \mathrm{H}\right.$ NMR, ${ }^{13} \mathrm{C}$ NMR, FT-IR, and GC-MS). The ${ }^{1} \mathrm{H}$ NMR and FT-IR spectra of products from all accomplished reactions are presented in Schemes 5 and 6, respectively. According to the results of the ${ }^{1} \mathrm{H}$ NMR spectroscopic method (Scheme $5 \mathrm{~A}$ ), a blended product was formed in the resulting reaction at (100:0) DEG:water ratio at $85 \%$ and $80 \%$ yields using nano- $\mathrm{TiO}_{2}$ and micro-TiO ${ }_{2}$, respectively (entry 1 in Tables 1 and 2; Supplementary Figure S1). Also, increasing the amount of water in the reaction medium at the ratio of (90:10) DEG:water, BPA as the main product and a blended product as a byproduct were formed (Scheme 5B) with a total yield of $75 \%$ and $73 \%$ using nano- $-\mathrm{TiO}_{2}$ and micro-TiO ${ }_{2}$, respectively (entry 2 in Tables 1 and 2; Supplementary Figure S2). In addition, the identification of carbonyl functional groups (1741 and $1739 \mathrm{~cm}^{-1}$ ) shown in the FT-IR spectrum (Scheme 6A, B) led to the presence of certain products in these ratios (entries 1 and 2 in Tables 1 and 2; Supplementary Figures S3 and S4). To identify the product quality in these ratios (entries 1 and 2 in Tables 1 and 2), without doing the purification steps described in Section 2.3, we used the GC-MS method for the mentioned ratios. The spectra resulting from the GC-MS do not exist in the other literature and are usually unavailable in the mass spectral libraries. However, according to the results GC-MS, all chemical structures of the corresponding compounds were derived from BPA certainly. On the other hand, based on a principle of symmetry, chemical structures may have symmetrically failed during the GC-MS process. Thus, due to the instability of the chemical structures according to mass spectrums, elucidation of the chemical structures of mass spectrums was made with the help of molecular ion peaks $\left(\mathrm{M}^{+}\right)$, important peaks and base peaks in the mass spectrums, and the mass spectrum of BPA. In Table 4 chemical structures identified by

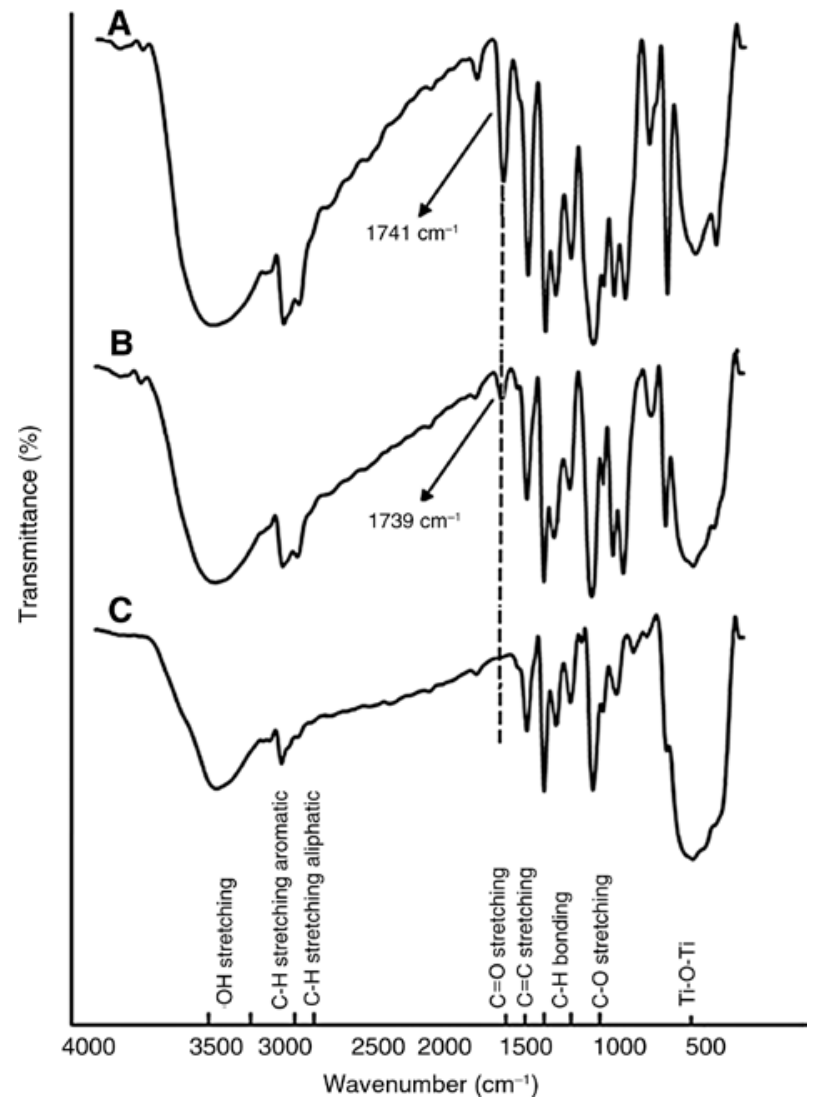

Scheme 6: FT-IR spectra in the $\mathrm{KBr}$ pellet: (A) Blended product resulting from the absence of water; (B) (BPA+ byproduct) is resulting from the $10 \%$ of water; (C) BPA resulting from more amount of water in the reaction medium.

GC-MS method are labeled. According to the results, the depolymerization reaction of PC wastes was not carried out completely in the (100:0) ratio of DEG:water (entry 1 in Table 1) due to lack of water in the reaction medium and only release of carbon dioxide $\left(\mathrm{CO}_{2}\right)$ from some of the products have taken place. Further, a mixture of diols such as etherified derivatives of BPA with molecular weight (MW) of 448-746 was detected in this ratio (Table 4, 1-6; Supplementary Figures S5-S10). According to the results of GC-MS, by increasing the water content at a ratio of (90:10) DEG:water, the reaction of depolymerization occurs incompletely in the BPA recovery (entry 2 in Table 1). Of course, a mixture of diols such as BPA and etherified derivatives of BPA with MW of 228-746 were identified in this ratio (Table 4, 7-14; Supplementary Figures S11-S18). Consistent with the main goals of the research, by adding more than $10 \%$ water to the reaction medium at other existing ratios in Tables 1 and 2, only pure BPA as the valuable material was obtained (entries 3, 4, 5, and 6 in Tables 1 and 2; Scheme 5C). Regarding the main goal of the research, to achieve the highest yield of BPA as a pure product, solvent 
Table 4: The molecules characterized using GC-MS.

\begin{tabular}{|c|c|c|c|}
\hline Entry & Molecules & MW & Retention time (min) \\
\hline 1 & $\begin{array}{l}\mathrm{HO}-\left(\mathrm{CH}_{2}\right)_{2}-\mathrm{O}-\left(\mathrm{CH}_{2}\right)_{2}-\mathrm{OCOO}-\mathrm{C}_{6} \mathrm{H}_{4}-\mathrm{C}\left(\mathrm{CH}_{3}\right)_{2}-\mathrm{C}_{6} \mathrm{H}_{4}-\mathrm{O} \\
\mathrm{COO}-\mathrm{C}_{6} \mathrm{H}_{4}-\mathrm{C}\left(\mathrm{CH}_{3}\right)_{2}-\mathrm{C}_{6} \mathrm{H}_{4}-\mathrm{OCOO}-\left(\mathrm{CH}_{2}\right)_{2}-\mathrm{O}-\left(\mathrm{CH}_{2}\right)_{2}-\mathrm{OH}^{\mathrm{a}}\end{array}$ & 746 & 15.055 \\
\hline 2 & $\begin{array}{l}\mathrm{HO}-\left(\mathrm{CH}_{2}\right)_{2}-\mathrm{O}-\left(\mathrm{CH}_{2}\right)_{2}-\mathrm{O}-\mathrm{C}_{6} \mathrm{H}_{4}-\mathrm{C}\left(\mathrm{CH}_{3}\right)_{2}-\mathrm{C}_{6} \mathrm{H}_{4}-\mathrm{OCOO}- \\
\mathrm{C}_{6} \mathrm{H}_{4}-\mathrm{C}^{-}\left(\mathrm{CH}_{3}\right)_{2}-\mathrm{C}_{6} \mathrm{H}_{4}-\mathrm{O}-\left(\mathrm{CH}_{2}\right)_{2}-\mathrm{O}-\left(\mathrm{CH}_{2}\right)_{2}-\mathrm{OH}^{\mathrm{a}}\end{array}$ & 658 & 13.246 \\
\hline 3 & $\begin{array}{l}\mathrm{HO}-\mathrm{C}_{6} \mathrm{H}_{4}-\mathrm{C}\left(\mathrm{CH}_{3}\right)_{2}-\mathrm{C}_{6} \mathrm{H}_{4}-\mathrm{OCOO}-\mathrm{C}_{6} \mathrm{H}_{4}^{-} \\
\mathrm{C}\left(\mathrm{CH}_{3}\right)_{2}-\mathrm{C}_{6} \mathrm{H}_{4}-\mathrm{O}-\left(\mathrm{CH}_{2}\right)_{2}-\mathrm{O}-\left(\mathrm{CH}_{2}\right)_{2}-\mathrm{OH}^{\mathrm{a}}\end{array}$ & 570 & 12.474 \\
\hline 4 & $\begin{array}{l}\mathrm{HO}-\left(\mathrm{CH}_{2}\right)_{2}-\mathrm{O}-\left(\mathrm{CH}_{2}\right)_{2}-\mathrm{OCOO}-\mathrm{C}_{6} \mathrm{H}_{4}-\mathrm{C}\left(\mathrm{CH}_{3}\right)_{2}- \\
\mathrm{C}_{6} \mathrm{H}_{4}-\mathrm{OCOO}-\left(\mathrm{CH}_{2}\right)_{2}-\mathrm{O}-\left(\mathrm{CH}_{2}\right)_{2}-\mathrm{OH}^{\mathrm{a}}\end{array}$ & 492 & 10.167 \\
\hline 5 & $\begin{array}{l}\mathrm{HO}-\mathrm{C}_{6} \mathrm{H}_{4}-\mathrm{C}\left(\mathrm{CH}_{3}\right)_{2}-\mathrm{C}_{6} \mathrm{H}_{4}-\mathrm{OCOO}-\mathrm{C}_{6} \mathrm{H}_{4}^{-} \\
\mathrm{C}\left(\mathrm{CH}_{3}\right)_{2}-\mathrm{C}_{6} \mathrm{H}_{4}-\mathrm{OH}^{\mathrm{a}}\end{array}$ & 482 & 11.248 \\
\hline 6 & $\begin{array}{l}\mathrm{HO}-\left(\mathrm{CH}_{2}\right)_{2}-\mathrm{O}-\left(\mathrm{CH}_{2}\right)_{2}-\mathrm{OCOO}-\mathrm{C}_{6} \mathrm{H}_{4}-\mathrm{C}\left(\mathrm{CH}_{3}\right)_{2}^{-} \\
\mathrm{C}_{6} \mathrm{H}_{4}-\mathrm{O}-\left(\mathrm{CH}_{2}\right)_{2}-\mathrm{O}-\left(\mathrm{CH}_{2}\right)_{2}-\mathrm{OH}^{\mathrm{a}}\end{array}$ & 448 & 10.167 \\
\hline 7 & $\begin{array}{l}\mathrm{HO}-\left(\mathrm{CH}_{2}\right)_{2}-\mathrm{O}-\left(\mathrm{CH}_{2}\right)_{2}-\mathrm{OCOO}-\mathrm{C}_{6} \mathrm{H}_{4}-\mathrm{C}\left(\mathrm{CH}_{3}\right)_{2}-\mathrm{C}_{6} \mathrm{H}_{4}-\mathrm{O} \\
\mathrm{COO}-\mathrm{C}_{6} \mathrm{H}_{4}-\mathrm{C}\left(\mathrm{CH}_{3}\right)_{2}-\mathrm{C}_{6} \mathrm{H}_{4}-\mathrm{OCOO}-\left(\mathrm{CH}_{2}\right)_{2}-\mathrm{O}-\left(\mathrm{CH}_{2}\right)_{2}-\mathrm{OH}^{\mathrm{b}}\end{array}$ & 746 & 15.535 \\
\hline 8 & $\begin{array}{l}\mathrm{HO}-\left(\mathrm{CH}_{2}\right)_{2}-\mathrm{O}-\left(\mathrm{CH}_{2}\right)_{2}-\mathrm{O}-\mathrm{C}_{6} \mathrm{H}_{4}-\mathrm{C}\left(\mathrm{CH}_{3}\right)_{2}-\mathrm{C}_{6} \mathrm{H}_{4}-\mathrm{OCOO}- \\
\mathrm{C}_{6} \mathrm{H}_{4}-\mathrm{C}\left(\mathrm{CH}_{3}\right)_{2}-\mathrm{C}_{6} \mathrm{H}_{4}-\mathrm{O}-\left(\mathrm{CH}_{2}\right)_{2}-\mathrm{O}-\left(\mathrm{CH}_{2}\right)_{2}-\mathrm{OH}^{\mathrm{b}}\end{array}$ & 658 & 15.106 \\
\hline 9 & $\begin{array}{l}\mathrm{HO}-\mathrm{C}_{6} \mathrm{H}_{4}-\mathrm{C}\left(\mathrm{CH}_{3}\right)_{2}-\mathrm{C}_{6} \mathrm{H}_{4}-\mathrm{OCOO}-\mathrm{C}_{6} \mathrm{H}_{4}-\mathrm{C}\left(\mathrm{CH}_{3}\right)_{2}- \\
\mathrm{C}_{6} \mathrm{H}_{4}-\mathrm{OCOO}-\left(\mathrm{CH}_{2}\right)_{2}-\mathrm{O}-\left(\mathrm{CH}_{2}\right)_{2}-\mathrm{OH}^{\mathrm{b}}\end{array}$ & 614 & 13.992 \\
\hline 10 & $\begin{array}{l}\mathrm{HO}-\mathrm{C}_{6} \mathrm{H}_{4}-\mathrm{C}\left(\mathrm{CH}_{3}\right)_{2}-\mathrm{C}_{6} \mathrm{H}_{4}-\mathrm{OCOO}-\mathrm{C}_{6} \mathrm{H}_{4}^{-} \\
\mathrm{C}\left(\mathrm{CH}_{3}\right)_{2}-\mathrm{C}_{6} \mathrm{H}_{4}-\mathrm{O}-\left(\mathrm{CH}_{2}\right)_{2}-\mathrm{O}-\left(\mathrm{CH}_{2}\right)_{2}-\mathrm{OH}^{\mathrm{b}}\end{array}$ & 570 & 12.2 \\
\hline 11 & $\begin{array}{l}\mathrm{HO}-\left(\mathrm{CH}_{2}\right)_{2}-\mathrm{O}-\left(\mathrm{CH}_{2}\right)_{2}-\mathrm{OCOO}-\mathrm{C}_{6} \mathrm{H}_{4}-\mathrm{C}\left(\mathrm{CH}_{3}\right)_{2}- \\
\mathrm{C}_{6} \mathrm{H}_{4}-\mathrm{OCOO}-\left(\mathrm{CH}_{2}\right)_{2}-\mathrm{O}-\left(\mathrm{CH}_{2}\right)_{2}-\mathrm{OH}^{\mathrm{b}}\end{array}$ & 492 & 10.125 \\
\hline 12 & $\begin{array}{l}\mathrm{HO}-\left(\mathrm{CH}_{2}\right)_{2}-\mathrm{O}-\left(\mathrm{CH}_{2}\right)_{2}-\mathrm{OCOO}-\mathrm{C}_{6} \mathrm{H}_{4}-\mathrm{C}\left(\mathrm{CH}_{3}\right)_{2}^{-} \\
\mathrm{C}_{6} \mathrm{H}_{4}-\mathrm{O}-\left(\mathrm{CH}_{2}\right)_{2}-\mathrm{O}-\left(\mathrm{CH}_{2}\right)_{2}-\mathrm{OH}^{\mathrm{b}}\end{array}$ & 448 & 8.487 \\
\hline 13 & $\mathrm{HO}-\mathrm{C}_{6} \mathrm{H}_{4}-\mathrm{C}\left(\mathrm{CH}_{3}\right)_{2}-\mathrm{C}_{6} \mathrm{H}_{4}-\mathrm{O}-\left(\mathrm{CH}_{2}\right)_{2}-\mathrm{O}-\left(\mathrm{CH}_{2}\right)_{2}-\mathrm{OH}^{\mathrm{b}}$ & 316 & 15.106 \\
\hline 14 & $\mathrm{HO}-\mathrm{C}_{6} \mathrm{H}_{4}-\mathrm{C}\left(\mathrm{CH}_{3}\right)_{2}-\mathrm{C}_{6} \mathrm{H}_{4}-\mathrm{OH}^{\mathrm{b}}$ & 228 & 11.214 \\
\hline
\end{tabular}

aln the absence of water (entry 1 in Table 1 ). ${ }^{b}$ In the presence of $10 \%$ water (entry 2 in Table 1 ).

mixture at (80:20) DEG:water ratio has been introduced as an environmentally friendly solvent mixture because pure BPA as a valuable material is achieved with the highest yield of $70 \%$ using nano- $\mathrm{TiO}_{2}$ and micro- $-\mathrm{TiO}_{2}$ as the solid supports (entry 3 in Tables 1 and 2).

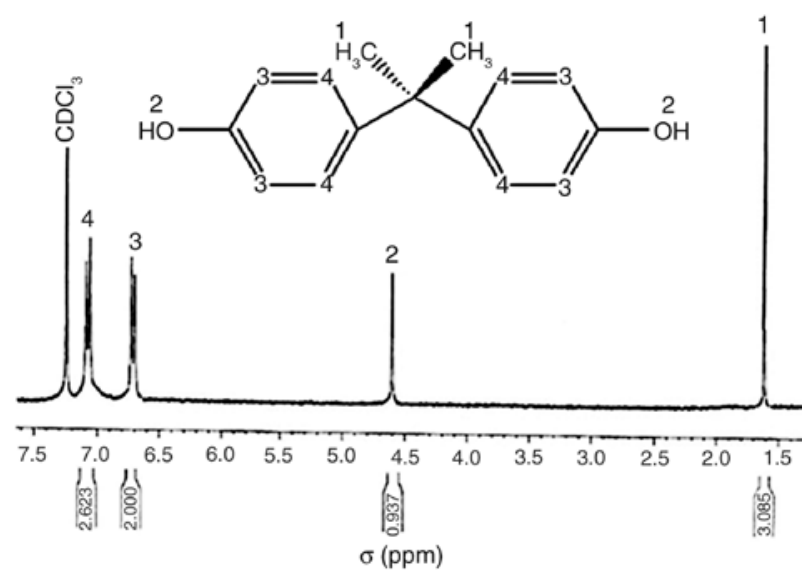

Scheme 7: ${ }^{1} \mathrm{H}$ NMR spectrum of recovered pure BPA in the $\mathrm{CDCl}_{3}$ solvent.

\subsection{Spectra analysis of recovered BPA}

4,4'-(Propane-2,2-diyl)diphenol (BPA). White powder, melting point (m.p.) $158^{\circ} \mathrm{C},{ }^{1} \mathrm{H}$ NMR (300 $\mathrm{MHZ}, \mathrm{CDCl}_{3}, \delta$ ): 7.10 (d, J=8.4, 4H; ArH), 6.71 (d, J=8.4, 4H; ArH), 4.60

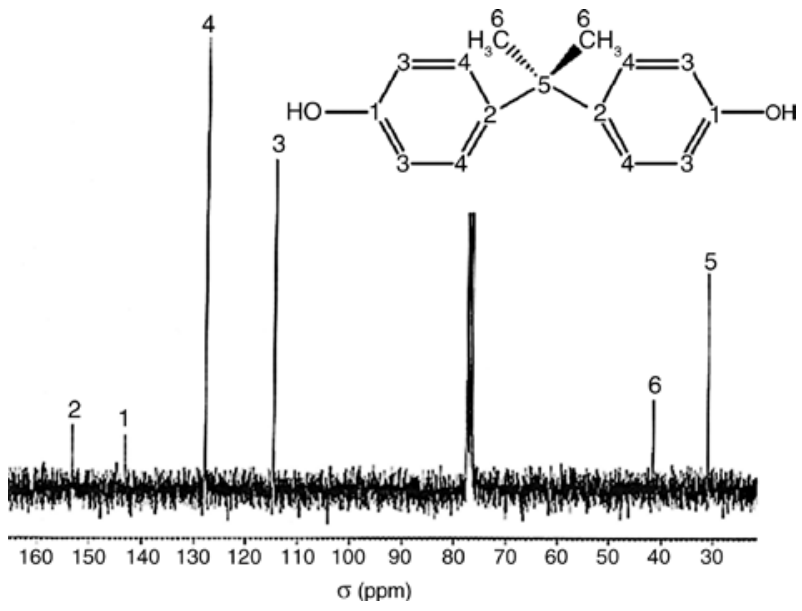

Scheme 8: ${ }^{13} \mathrm{C}$ NMR spectrum of recovered pure BPA in the $\mathrm{CDCl}_{3}$ solvent. 
(s, 2H; OH), 1.61 (s, 6H; $\mathrm{CH}_{3}$ ) (Scheme 7; Supplementary Figure S19). ${ }^{13} \mathrm{C}$ NMR (300 MHz, $\left.\mathrm{CDCl}_{3}, \delta\right): 153.26,143.26$, 127.94, 114.69, 41.68, 31.07 (Scheme 8; Supplementary Figure S20). FT-IR (KBr pellet press): $1360-1507 \mathrm{~cm}^{-1}(\mathrm{C}-\mathrm{H}$ bending), $3100 \mathrm{~cm}^{-1}$ (C-H stretching aromatic), $2962 \mathrm{~cm}^{-1}$ (C-H stretching aliphatic), 3150-3450 $\mathrm{cm}^{-1}$ (OH stretching), $1178-1236 \mathrm{~cm}^{-1}$ (C-O stretching), $1602 \mathrm{~cm}^{-1}$ (C=C stretching), $679 \mathrm{~cm}^{-1}$ (Ti-O-Ti) (Scheme 6C; Supplementary Figure S21). The FT-IR spectrum fully corresponds with NMR data.

\section{Conclusion}

In summary, in this study the performance of nano- and micro- $\mathrm{TiO}_{2}$ as an efficient solid support in the chemical recycling of PC wastes by using a binary system (DEG/ water) mixture as green solvents and $\mathrm{NaOH}$ as alkali metal catalyst for the recovery of BPA and etherified derivatives of BPA were investigated. As is fully explained, the main goal of this research is to achieve pure BPA as the valuable material. According to the results, using micro- $\mathrm{TiO}_{2}$ as a solid support compared with the nano- $\mathrm{TiO}_{2}$ with lowering of the surface area and active sites required for the reaction, due to a reduction of the surface to volume ratio, a significant increase occurs in the reaction time. Moreover, when increasing the amount of DEG in mixture solvents because of the higher power of the alkoxideion than hydroxideion as the nucleophile, the reaction time decreases. On the other hand, the increase of DEG in the solvent mixture leads to the chemical recycling of $\mathrm{PC}$ wastes into a blended product or mixed products (BPA+ etherified derivatives of BPA), which is not optimal for the main goals of the research. In these reactions, water is known as an important agent in order to complete the depolymerization reaction of PC wastes in achieving the pure BPA as the valuable material. In addition, when decreasing the $\mathrm{NaOH}$ concentration as an alkali metal catalyst in the reaction medium, the reaction time for chemical recycling of PC waste increases significantly. The effect of recovering nano- $\mathrm{TiO}_{2}$ from products for four cycles without significantly reducing the yields of products has been investigated. This method is an appropriate way to convert PC wastes into pure BPA as valuable materials with features such as inexpensive cost, highefficiency products, recyclability of solid support, safe, eco-friendly, simple, easy, and using green solvents and available in atmospheric pressure. Finally, our research group hopes to look at the performance of other reagents, nanoparticles, and green solvents on the chemical recycling of PC wastes in the future.
Acknowledgements: We gratefully acknowledge the financial support of the Imam Khomeini International University.

\section{References}

[1] Oku A, Tanak S, Hata S. Polymer 2000, 41, 6749-6753.

[2] Pinero R, Garcia J, Cocero MJ. Green Chemistry 2005, 7 , 380-387.

[3] Chiu S, Chen S, Tsai C. Waste Manage. 2006, 26, 252-259.

[4] Pant D. Process Saf. Environ. Prot. 2016, 100, 281-287.

[5] Iannone F, Casiello M, Monopoli A, Cotugno P, Sportelli MC, Picca RA, Cioffi N, Dell'Anna M, Nacci A. J. Mol. Catal. A: Chem. 2017, 426, 107-116.

[6] Li B, Xue F, Wang J, Ding E, Li Z. Prog. Rubber, Plast. Recycl. Technol. 2017, 33, 39-50.

[7] Grause G, Sugawara K, Mizoguchi T, Yoshioka T. Polym. Degrad. Stab. 2009, 94, 1119-1124.

[8] Liu FS, Li Z, Yu ST, Cui X, Xie CX, Ge XP. J. Polym. Environ. 2009, 17, 208-211.

[9] Liu FS, Li Z, Yu S, Cui X, Ge X. J. Hazard. Mater. 2010, 174, 872-875.

[10] Jie H, Ke H, Qing Z, Lei C, Yongqiang W, Zibin Z. Polym. Degrad. Stab. 2006, 91, 2307-2314.

[11] Song X, Liu F, Li L, Yang X, Yu S, Ge X. J. Hazard. Mater. 2013, 244, 204-208.

[12] Kim D, Kim BK, Cho Y, Han M, Kim BS. Ind. Eng. Chem. Res. 2009, 48, 685-691.

[13] Beneš H, Paruzel A, Trhlíková O, Paruzel B. Eur. Polym. J. 2017, 86, 173-187.

[14] Taguchi M, Ishikawa Y, Kataoka S, Naka T, Funazukuri T. Catal. Commun. 2016, 84, 93-97.

[15] Hu LC, Oku A, Yamada E. Polymer 1998, 39, 3841-3845.

[16] Liu F, Li L, Yu S, Lv Z, Ge X. J. Hazard. Mater. 2011, 189 , 249-254.

[17] Quaranta E, Sgherza D, Tartaro G. Green Chem. 2017, 19, 5422-5434.

[18] Hata S, Goto H, Yamada E, Oku A. Polymer 2002, 43, 21092116.

[19] Hatakeyama K, Kojima T, Funazukuri T. J. Mater. Cycles Waste Manage. 2014, 16, 124-130.

[20] Blazso M. J. Anal. Appl. Pyrolysis 1999, 51, 73-88.

[21] Šala M, Kitahara Y, Takahashi S, Fujii T. Chemosphere 2010, 78, 42-45.

[22] Antonakou EV, Kalogiannis KG, Stephanidis SD, Triantafyllidis KS, Lappas AA, Achilias DS. Waste Manage. 2014, 34, 2487-2493.

[23] Tagaya H, Katoh K, Kadokawa JI, Chiba K. Polym. Degrad. Stab. 1999, 64, 289-292.

[24] Watanabe M, Matsuo Y, Matsushita T, Inomata H, Miyake T, Hironaka K. Polym. Degrad. Stab. 2009, 94, 2157-2162.

[25] Tsintzou GP, Antonakou EV, Achilias DS. J. Hazard. Mater. 2012, 241, 137-145.

[26] Deirram N, Rahmat AR. APCBEE Procedia 2012, 3, 172-176.

[27] Rosi L, Bartoli M, Undri A, Frediani M, Frediani P. J. Mol. Catal. A: Chem. 2015, 408, 278-286.

[28] Alavi Nikje MM, Askarzadeh M. Polimery 2013, 58, 27-29. 
[29] Alavi Nikje MM, Askarzadeh M. Polímeros 2013, 23, 29-31.

[30] Alavi Nikje MM, Askarzadeh M. Prog. Rubber, Plast. Recycl. Technol. 2014, 30, 129-136.

[31] Alavi Nikje MM, Askarzadeh M. Prog. Rubber, Plast. Recycl. Technol. 2013, 29, 169-176.

[32] Alavi Nikje MM. Polimery 2011, 56, 35-38.
[33] Shaikh SF, Mane RS, Min B, Hwang Y, Joo O. Sci. Rep. 2016, 6, 20103-20113.

[34] Massart R. IEEE Trans. Magn. 1981, 17, 1247-1248.

Supplementary Material: The online version of this article offers supplementary material (https://doi.org/10.1515/gps-2018-0028). 